MedieKultur | Journal of media and communication research | ISSN 1901-9726

Article - Theme section

\title{
Mainstreaming and misfitting Exploring disability and its intersection with gender in online disability awareness-raising videos
}

\section{Maria Bee Christensen-Strynø}

MedieKultur 2016, 61, 58-75

Published by SMID | Society of Media researchers In Denmark | www.smid.dk The online version of this text can be found open access at www.mediekultur.dk

\begin{abstract}
This article investigates how the concepts of 'mainstreaming' and 'misfitting' become useful analytical tools for analyzing visual media representations of disability. The analysis deals with two videos from online awareness-raising campaigns about disability, and the aim is to show that disability intersects with gender in ways that have significant consequences for how bodily expressions are negotiated. Media representations of both disability and gender have become more visible but are rarely studied together. When they are, it is rarely from a vantage point in disability experience. Therefore, I stress the importance of applying intersectional approaches specifically to disability and suggest a methodological framework composed of two contrasting movements: mainstreaming (as a reference point of striving for normalization in visual media representation) as opposed to misfitting (as a critical position that applies to disability and its intersection with gender). The analyses of the videos show how these positions are at play through sometimes very subtle capacities in which gender interferes with the processes of mainstreaming and stabilizing disability, or attempts are made to accommodate misfit positions by challenging and transgressing traditional notions of disabled and gendered embodiment.
\end{abstract}




\section{Introduction: Making disability the starting point}

Disability has traditionally been displayed and represented through certain recurring cultural tropes, discourses and stereotypical modes of visualization, which have repeatedly been - and are still being - criticized in cultural and media analyses of disability (e.g., Garland-Thomson, 1997, 2002; McRuer, 2006; Clare, 2015; Ellis \& Goggin, 2015; Ellis, 2012, 2015). Similarly, in a genealogy of visual gender representation, stereotyping and subjugating women and female figurations have been the focus of many critical examinations. Visual art and film identifications of embedded gendered and sexualized spectator positions, such as the male gaze and voyeurism (Berger, 1972; Mulvey, 1989), have been central in establishing an analytical tradition of criticizing imbalances of power and marginalized locations in visual representation (Rose, 2016).

These similarities could very well be developed to pose as an argument for engaging an intersectional lens of disability and gender on issues related to visual media representation. Yet, I find it to be important that the internal relationship between the two fields is also marked by the fact that gender studies is the more well-established discipline, while disability studies may still be considered to be a relatively new field in critical studies of oppressed minority identity and embodiment, especially in relation to traditions of intersectionality (Meekosha \& Shuttleworth, 2009).

I mention this in order to support my specific theoretical line of inquiry in which I am concerned with disability and its intersection with gender but the study of disability representation is the main point of entry. Thus, foregrounding disability is not necessarily a given as it is still a field unknown to many scholars and media users who are otherwise interested in social and cultural disparity and inequality. At the same time, the point is not to safeguard the borders of disability to ensure its legitimacy but to acknowledge and try to understand the significance of dynamics that extend beyond the defined boundaries of the field.

The scope of my empirical investigation is the visual media representation of disability in two online videos from two different disability awareness-raising campaigns: "The Raw Beauty Project" and "Born Risky". Both campaigns represent contemporary visualizations of disability, and the individual videos are specifically produced to raise awareness about disability. However, they are also both imbued with either expectations or rebuttals of ideal bodies, sexualities and interpersonal relations, making them explicitly noteworthy in a context of gender representation.

The choice of online videos was made to show that disability matters are becoming more and more integrated into online media cultures (Ellis, 2015). Accessible via YouTube and Vimeo and shared across well-known social media sites and online platforms, both videos could be categorized as what has been called "next generation television" (Urrichio, 2009, p. 35); but, in terms of aesthetics and style, the specific videos also represent different ways of communicating disability awareness: One is an audio-visual montage of interview clips, the other a music video. 
Furthermore, selecting online video for analysis helps recognize and highlight how subcultural movements, where I place disability awareness-raising, are claiming space by making use of mainstream visual media formats and genres through online communication (Poell \& van Dijck, 2015). In this sense, the videos are also part of displaying a process in which disability, as an increasingly complex social phenomenon, is gaining more significance and visibility in the media (Ellis \& Goggin, 2015).

Exploring disability in a context of online video, thus, highlights an interesting contrast by using a mainstream visual media format to represent subcultural imagery, which has inspired the methodological framework chosen for the analysis. Here, I make use of the concepts 'misfit' and 'misfitting' (Garland-Thomson, 2011), and I link them to the terms 'mainstream' and 'mainstreaming'. The correspondences and contrasts between them, I argue, form an analytical prism that applies well to an intersectional-oriented analysis of disability and gender.

The article is structured in three main parts. First, I offer an overview of central theoretical movements and research developments in the cultural field of disability and its connections to visual media representation. This part also encompasses a section with theoretical concerns specifically about intersectionality in relation to disability. Second, I introduce the methodological framework in which I clarify how the concepts of mainstreaming and misfitting can be operationalized to analyze visual media representations of disability and gender. Finally, I analyze and discuss the two videos. In particular, I pay analytical attention to the ongoing orchestrations and negotiations of disability where it intersects with gender. In the first video, the main point is to demonstrate how generic and normalized understandings of femininity are re-inscribed and justified as an attempt to mainstream and stabilize disability as an identity category. In the second video, I point to how the instabilities of both disability and gender as negotiable categories of identity are visualized as productive forms of diversity that challenge and transgress traditional notions of disabled and gendered embodiment.

\section{The cultural field of disability: Zooming in on visual media representation}

Disability studies is a flourishing field in which many important aspects of disability experience and embodiment have come to light (Siebers, 2008; Goodley, 2013; Adams, 2013). In particular, the representation of disability in visual media and popular culture has become an area of scholarly interest and attention (e.g., Goodley et al., 2012; Ellis, 2015).

Seeing disability as a substantial cultural trope is basically to take seriously and to valorize the fact that cultural locations and aesthetic disciplines - such as literature, theatre, film, television productions, visual art and new media - are significant contributors to, as well as manufacturers of, how disabled embodiment, corporeality and identity formation are constantly (re)produced, contested and (re)negotiated (Garland-Thomson, 2002). 
It is relevant to note that, within disability studies, the shift towards the cultural field grows out of a long battle to relocate the fundamental awareness of disability away from dominant discourses of pathology and medicalization, known as the medical model of disability, towards a recognition of disability as subject to socially-created oppression, called the social model of disability (Garland-Thomson, 1997; Goggin \& Newell, 2003; Siebers, 2008; Goodley, 2011, 2013). In disability studies, one of the basic issues has been to challenge the medical model's way of regarding disability as a problematic and unstable bodily condition connected to biological defects that, if possible, should be cured or eradicated (Siebers, 2008, p. 3f.). Hence, the rise of the social model expresses a critical shift in focus in which disability moves "from the realm of medicine into that of political minorities" (GarlandThomson, 1997, p. 6). In short, disability is recast from an individual's problem to a sociocultural and political issue.

Though widely appreciated, the social model has also been challenged in recent years by disability scholars and activists who have begun to acknowledge the inadequacies in the binary way of distinguishing the physical realities of impairment from the social constructions of disability (Goodley, 2013). Consequently, scholars have raised questions about how it is possible to account for aspects of physical as well as emotional pain connected to the carnal body (Siebers, 2008, pp. 59ff.) or the possible joys of creating, participating in and consuming popular culture (Ellis, 2015, p. ix). The cultural field of disability has, thus, grown to become an increasingly complex arena in which ongoing processes of challenging and assessing conflicting and ambiguous discourses and models of disability continually unfold (Garland-Thomsen, 2002; Goodley, 2013).

Critical culture and media-oriented branches of disability studies have been evolving in a variety of research literature and special-issue journals in recent years. Whereas some scholars have analyzed how disability has become more visible because of a heightened attention on diversity as a commercial strategy in TV advertisements (Haller \& Ralph, 2006), others have focused on how subversive capacities of alternative filmmaking are instrumental in influencing and promoting the advancement of more sophisticated visual representations of disability (Hladki, 2009). It has also been pointed out that popular cultural imageries of the cyborg should be considered as a productive resource in the ways people understand and relate to people with disabilities (Goodley et al., 2012), while empirical research surveys have demonstrated that visual media representations have a substantial impact on the self-identity formation of people with disabilities (Zhang \& Haller, 2012). In the context of visual representation through mainstream TV shows and new media, it has been claimed that reality television and online blogging contribute to a broader space for renegotiating disability through the exchange of political beliefs and personal opinions and experiences (Ellis, 2014, 2015).

The basic link between the cultural field of disability and visual media representation in all of these frameworks is the element of negotiating understandings and definitions of disability, specifically through different forms of visual media. My investigation of disability 
representation in the online videos is, thus, situated in a direct extension of these movements in the cultural field of disability in which the ascription of value to the significance of visual representation is a prerequisite.

\section{Theoretical remarks on intersectionality in relation to disability}

Disability and disability studies also co-exist in a variegated landscape of identity politics and research where medical, social and cultural discourses of disability are often deeply intertwined with other discourses of marginalized identity and embodiment, such as gender, queer, race, ethnicity, class, obesity, ageing, etc. A shared interest for all of these fields is to challenge the configurations and regulations of material reality and social discourses of normality and the interrelatedness between these areas is also sometimes seen in the light of how the more particular interests of one field overlap another (Adams, 2013; Goodley, 2013; Mohamed \& Schefer, 2015).

Some disability-oriented research and writing are marked by an affinity with gender and queer studies; and, for certain scholars, perspectives of disability ascend directly from a gendered point of departure (e.g., Garland-Thomsen, 2002; McRuer, 2006; Campell, 2009). Hence, it is not unusual for the binary distinction between sex and gender to be mentioned as the equivalent of the separation of impairment and disability as an extended frame of understanding bodies through physical conditions as opposed to bodily deviation, understood as processes of social discursive formations (Garland-Thomson, 2011, pp. 591f.; Siebers, 2008, pp. 53ff.). Historically, disability is also often linked to the civil and women's rights movements in the US and UK (Goodley, 2013). While these ways of mirroring historical and conceptual developments are useful in understanding and explaining important similarities and shared challenges between the fields, more direct intersectional perspectives on disability and gender often tend to recede into the background (Adams, 2013; Mohamed \& Schefer, 2015).

Intersectionality, as the term was coined by Kimberlé Crenshaw (1991), explores the overlapping connections between race and gender in order to create more complex understandings of the challenges faced by black women.

The argument for engaging in disability and its intersections with gender is an accentuation of the same reasoning: that human beings exist on multiple, interlinked axes of identity and embodiment that produce intricate understandings of disability existence.

In disability studies, scholars have begun to call for more intersectional analysis; and, slowly but steadily, an increasing amount of literature seems to find its way forward (e.g., Ben-Moshe \& Magaña, 2014; Mohamed \& Schefer, 2015; Moodley \& Graham, 2015). In a recent special issue of the South African feminist journal Agenda: Empowering women for gender equity (vol. 29(2) (2015)), attention is specifically directed to intersections of disability and gender. The topics addressed here, however, mostly relate to socio-political issues such as disabled, gendered and racialized disparities in education, sexual crimes and parenting. 
While these are, indeed, relevant topics, I would also like to stress the need and importance of applying intersectional approaches to matters of disability in the field of visual media. In this regard, I lean on Crenshaw's definition of representational intersectionality whereby imageries and narratives from media and popular culture are ascribed value in uncovering important intersectional aspects of identity formation in relation to race and gender (1991, pp. 1282f.). Similarly, this could also be a more distinct focus in disability studies.

When foregrounding disability, as I do here, however, it is important to mention that, while several scholars within disability studies build upon and draw on theories of gender, sexuality and race, they also frequently challenge and point to the ways disability is neglected by these traditions (Kafer, 2013; Mohamed \& Schefer, 2015).

An example of this is Adrienne Rich's feminist essay "Compulsory Heterosexuality and Lesbian Existence (1980)" (2003) in which lesbian existence is interpreted as a necessary but overlooked - extension of feminism. This particular essay has been critically contested by the queer-feminist disability scholar Alison Kafer, who in her essay "Compulsory Bodies: Reflections on Heterosexuality and Able-Bodiedness" points out that disability almost always appears as the "negative other" in relation to female gender and sexuality (2003, p. 84). Kafer and other disability studies scholars have also argued that Donna Haraway's classification of the cyborg is a product of able-bodied logics that do not consider the physical and emotional realities and the particularities of disabled embodiment (Siebers, 2008, p. 63; Kafer, 2013, p. 105).

Thus, on one hand, I wish to emphasize that seeing disability through its intersection with gender might shed light on the subtle implications and tensions that occur as a part of everyday life in which identities and bodies are not purely monolithic and well-defined possessions (Ben-Moshe \& Magaña, 2015). On the other hand, one should keep in mind that employing an intersectional lens to grasp critically the complexities and fluidities of existing bodies and identities is also limited through its own cuts and sections.

\section{A methodological framework of mainstreaming and misfitting}

The concepts of misfit and misfitting were coined by the feminist disability studies scholar Rosemarie Garland-Thomson (2011). Expanding on her thoughts, I make use of these concepts in my analysis. However, instead of fully adopting Garland-Thomson's conceptual framework, which is composed of the dichotomy of misfitting vs. fitting, I shift the attention a bit by linking her concepts to the terms mainstream and mainstreaming.

Raising awareness is about communicating knowledge - often with an aim of creating social change (Sayers, 2006; Rice \& Atkin, 2013). In relation to disability, this has apparent connections to the terms mainstream and mainstreaming.

'Mainstream' refers to areas that are commonly considered popular or generally accepted and, thus, are a reservoir of societal norms (e.g., "the able-bodied mainstream society", Ellis, 2012, p. 82). The term is also frequently used in connection with media and popular culture 
(e.g., "the infrastructures of new media that have now become mainstream", Beer, 2013, p. 79).

In the context of disability, mainstreaming has come to denote different processes of inclusion that have been a regularly emerging key issue in relation to disability rights and policymaking - for instance, in areas of education and housing. Gerard Goggin and Christopher Newell, authors of the book Digital Disability (2003, p. 135), connect mainstreaming to new media by pointing to the protracted processes of disability inclusion and accessibility online. My interest in the concepts of mainstream and mainstreaming relates exactly to these notions of striving for normality through inclusion in visual media representation, which seem in the videos to be directly associated with the pursuits for change. In the analyses of the videos, this notion of visual mainstreaming occurs as an underlying objective of raising awareness on disability.

However, invoking change also contains an inherent critique of the status quo. Hence, the videos are explicitly critical of the ways in which disability is represented in visual media. This can be understood on the basis of the often conventional and culturally inscribed ways disability is represented through stereotypical and simplified visualizations. Katie Ellis and Gerard Goggin, the authors of the recent volume Disability and the Media (2015, pp. 57ff.), point to media representation as a core issue in disability studies in which bodily particularities of disability are rarely encountered without explanations. This has often left people and characters with disabilities - especially, in popular culture and news media in situations in which they are primarily defined by their disabilities. Yet, according to Ellis and Goggin, media representation of disability is also becoming increasingly complex due to the growth of new media ecologies that change traditional participation and reception (2015, pp. 39f. and 84ff.). In this regard, mainstreaming disability is also about creating new visual languages and methods that challenge traditional stereotypes and allow disability to inhabit positions that are gradually becoming more dynamic.

According to Garland-Thomson (2011), it is possible to bring forward the productive particularities of disability through her conceptualization of the term 'misfit', which she has labeled a feminist materialist disability concept. She explains that the notions of being misfit and the states of misfitting offer a dynamic and process-oriented framework that confronts traditional devaluations of disabled embodiment while still taking into account that the materiality of the body is governed by particular and individual needs and limitations.

Inspired by the work of Karen Barad on new materialistic feminism, Garland-Thomson identifies misfit as a form of "material-discursive becoming" (2011, p. 592). This she clarifies by shifting the conventional ideas of social constructionism, which are mostly considered to be a matter of discourses and interpretation (in the sense of language and representation). Instead, she advocates a broader understanding of physical and social phenomena as being dynamically interrelated by claiming all materiality is inhabited by fluctuating agencies (ibid.). 
By referring to misfit as an encounter of disjunction, it becomes clear that misfit and misfitting are always in an indissoluble relation to fit and fitting in which the same person may experience misfitting or fitting, depending on the situation. In this manner, the notion of misfit encapsulates the fluent and contextual nature of more recent understandings and models of disability and the regulating work of normality, which have to do with social attitudes and physical settings and the ways bodies are situated in time and space.

Identifying the incongruent relation between misfit and fit as ever-changing variables between physical, social and cultural states of body and world also relativizes the fixed binary of disability versus ability. This creates a framework in which an array of possible intersections of identity and bodily vectors are made possible. On this, Garland-Thomsen notes:

\begin{abstract}
Although misfit is associated with disability and arises from disability theory, its critical application extends beyond disability as a cultural category and social identity toward a universalizing of misfitting as a contingent and fundamental fact of human embodiment (Garland-Thomsen, 2011, p. 598).
\end{abstract}

Furthermore, Garland-Thomson also links her reflections on misfitting and fitting directly to the visual sphere by pointing out that a fit produces visual anonymity as "a predominantly unmarked and unrecognized way of being in the world" (2011, p. 596). In this sense, fitting is the 'majorized', privileged and dominant subject position that sustains material and visual anonymity. Thus, making misfit identity more visible is also a way to recognize visual particularity as a general part of human embodiment.

My interest in misfitting, then, is how, in the context of the disability awareness-raising videos, it seems to allow and support a shift from a conventional analytical focus on bodily peculiarity and compensatory logics to projections of the productive potentials of visual particularity and how this possibly feeds into processes of visually mainstreaming disability.

The contrasting parallel of mainstreaming and misfitting, thus, forms a double-sided analytical lens that puts emphasis on the ways disability is being expressed and negotiated in the awareness-raising videos in terms of preserving and challenging notions of disability through its intersections with gender. What becomes interesting, in particular, is that being misfit in a context of disability does not necessarily seem to rule out being mainstream in a context of gender. In this sense, the two concepts constitute a framework that makes possible an articulation of the contrasting movements taking place in the videos.

\title{
The Raw Beauty Project NYC and Born Risky
}

The two videos are both from campaigns that were launched in 2014. The first video was released in the spring as a part of the still ongoing awareness-raising and outreach project "The Raw Beauty Project", which is described on the official website as "an innovative 
visual arts project designed to celebrate the lives of women with disabilities, redefining and unleashing potential from all women" (rawbeautynyc.com).

At the time of its launch, the project consisted of photographic images and personal biographies of 20 different women from New York City that have since been exhibited in various places in North America as well as in online and print media. The project is a travelling exhibition but is primarily presented online. Activities such as updates on scheduled exhibitions and calls for new (role) models and photographers are managed from the offcial website and from a Facebook profile, which also has the function of being a gathering point in which the profile wall is being used for linking to related news, projects and campaigns. The actual photographic material and the bios are also available on the webpage together with the promotional YouTube video that is the subject of investigation here.

The second video is a music video for the original song "Prototype" performed by the Latvian-British singer-songwriter and pop artist Viktoria Modesta. It was released in December 2014 when British Channel 4 pre-launched a large-scale brand campaign by revealing a clip from the music video in an advertisement break during the live broadcasting of the national $X$ Factor finals on the commercial channel ITV. The music video, produced specifically for the campaign with the edgy title "Born Risky", ${ }^{2}$ was subsequently released on Channel 4's webpage, online platforms and Viktoria Modesta's own webpage.

Beyond representing different visual genres and aesthetics, a formal distinction between the two videos is that the one from The Raw Beauty Project was created by a small-scale independent organization of women with disabilities in the US, while the other, from the Born Risky campaign, was initiated by an established media broadcasting collaboration in the UK. This difference indicates the span of today's communication practices and underscores a shift in the distribution of media power due to online and social media in which activist and commercial interests exist side by side and in confluence (Poell \& van Dijck, 2015).

\section{Raw beauty - Mainstreaming disability through gendered beauty-ism}

The 4:52 minutes long video functions as a promotional piece in which a number of women speak about their own stories and their views on the project and reasons for participating. Visually mixing traditional personal portrait interview clips with scenes documented from the making of the photographic ventures in which some of the participating women are depicted while modeling for different photographers, the spectator is offered a dynamic way of piecing together the message of the project. Some of the key statements given by the women depicted in the video are:

One of the things that really excites me about The Raw Beauty Project is that it turns the traditional sense of beauty upside down (0:17-0:26). 
We're tapping into a world that is unseen in media (0:37-0:39).

There's a societal perception of what beauty is - and what sensual is - and what sexual is and that doesn't seem to go with a woman with a disability (2:05-2:22).

Part of the mission of the Raw Beauty Project is that we want to transform stereotypes of women with disabilities (3:41-3:47).

Through these verbal statements, the video clearly addresses a misfit between society's notion of beauty and women with disabilities, which is up for negotiation. From a disability and gender intersectional point of view, it makes sense to claim that disability challenges traditional notions of female beauty, especially when one thinks about the number of scholars who have directly pointed out that women with physical disabilities are generally considered to be asexualized, infantilized and less feminine than women without disabilities (e.g., Goodley, 2013; Mohamed \& Schefer, 2015). This also resonates well with the examples of verbal statements above. In this sense, the video articulates a valuable critique of how disability is rarely acknowledged in relation to gendered positions of female beauty. By creating the video, The Raw Beauty Project explicitly aims at filling in important gaps in disability representation. In this connection, however, it is quite interesting how the women in the video are portrayed visually. All of the women depicted are glamorously styled with elegant makeup and voluminous hairstyles. They wear classic gowns and jewelry while posing in soft studio lightning. The styling is not over-exaggerated but connotes a distinct sense of sophistication, gracefulness and traditional femininity. It becomes obvious that the ideals of female beauty are actually being carried forward by some very generic and mainstream visual stereotypes about women.

The way traditional female beauty imagery is being altered is that all of the women have visible signifiers of disability (i.e., they are wheelchair users or amputees); and, by mainstreaming their appearances through such styling, The Raw Beauty Project seems to want to challenge the general notions about who are fit and have the rights to exercise mainstream beauty. However, the smoothness of the imagery does seem to create some points of friction with the women's verbal statements. Thus, "turn[ing] the traditional sense of beauty upside down" does not exactly comply with the visual expressions of traditional and well-groomed femininity. It can be noted that there are actually obvious differences in age, body type and racial representation that could also be considered crossing the lines of traditional femininity. However, since the intended, pronounced aim is to challenge stereotypes of women with disabilities, these connotations seem to be scaled down.

One of the core elements that has some ambivalence is the term 'raw' in connection with 'beauty'. At the end of the video, this is articulated as a collective claim in which all the women appear, one by one, stating: "I am [their name] - and I am raw beauty" (4:15-4:37). This approach of giving voices to and making visible a larger group of women can be interpreted as a way to display shared empowerment in order to create identification. Although 
creating a sense of unity as an empowering feature, the intention of this statement is not perfectly clear.

First of all, 'raw' seems to be selected as an obvious contrast to the term 'beauty', evoking associations with the well-known metaphorical phrase of being 'a diamond in the rough', which explains naturally occurring beauty hidden in diamonds before they are cut and polished. In this way, raw is equated with disability, implying that disabled embodiment is potentially a raw form of beauty but aligning beauty with the traditional visual styling and expression makes raw a somewhat hollow term.

It seems as if raw is chosen to be a term that can bring the misfit between disability and beauty into a state of negotiation. However, this becomes problematic since the norms of female beauty itself go unchallenged, which causes a discrepancy. When raw and disability are linked together, it is as if the situation of performing a gendered role of classic femininity magically repeals the anticipated incompatibility between disability and beauty. Hence, the salient effect of the traditional beauty representation is that the visual experience of the video is pleasant - but also without resistance - in a sense in which the traditional connotations of female beauty actually smooth out the instabilities - or the rawness - of bodies with disabilities. In this manner, the video establishes a visuality in which the spectator remains undisturbed by disability due to the mainstreaming of the depicted bodies by inscribing them into conventional gendered (i.e., feminized) roles that are not in any way overstated or out of the ordinary.

Mainstreaming disability, thus, becomes a question about eliminating the misfit between disability and female beauty instead of making space for new possible ways of imagining beauty. Interestingly, the video displays how disability is, then, mainstreamed through a gendered position and how this is unobtrusively consistent with the promotional video format that allows for a framing of the project in an informal, propulsive and spunky manner, thus supporting the regulation of a compelling mainstream visuality. In the Raw Beauty Project, "transform[ing] stereotypes of women with disabilities" is, then, about acknowledging that women with disabilities can live up to notions of traditional female beauty, which may also serve a purpose on its own.

\section{Viktoria Modesta and Born Risky - coalescent positions of disability and gender}

The music video immediately announces its intention to renegotiate disability through a text-based introduction, proclaiming: "Forget what you know about disability / Channel 4 presents / a new kind of pop artist / Viktoria Modesta". This is followed up in the end of the video that concludes: "Some of us were born to be different / Some of us were born to take risks / Born Risky \#bornrisky" (bornrisky.com).

The audio-visual construction of the video, especially in the intro and outro, is a demonstration of a hyper-aestheticized and theatrical suspense. The intro sequence contains a 
static black screen on which the bits of text cited above fade in and out of the frames. All the while, an increasingly rhythmic stomp with a shifting hollow and metallic sound takes up the auditory space. A single crosscut to a scene displaying a highly-polished glass-like floor interrupts the black screen, and the sound of the stomp is united with the image of a pair of legs in motion. With a shot cropped right above the knees at the top of the image frame, one bare leg is exposed, adorned with a stylish, glossy black platform shoe. The other leg, in the act of taking a step, appears as a black metal spike, sharp as a needle, and makes a shrill, dramatic sound as it hits the floor, whereupon the screen goes black. Similarly, the outro sequence is a visual expansion of the intro in which the setting is a return to the unspecified shiny floor across which the same pair of legs walks, accompanied by the same heavy rhythmical stomps. This time, the scene cuts to a framing of Modesta's upper body, theatrically masked in a 'futuresque' pink costume and a black visor helmet, verifying that the stomping legs are hers. The intensity increases as Modesta continues to stomp, eventually causing cracks where the spike hits the floor; and, with a final, determined stomp, the light shifts to a staged luminous shade of red followed by full-body images of Modesta. She now appears in a black ballet costume, tied up in strings like a puppet from a non-visible ceiling while performing gracious ballet swirls and moving around with an almost spiderlike swiftness and unpredictability. In the end, the screen goes black, and the concluding statement appears.

In between the rather extensive intro and outro, the actual music video is a characteristic contemporary up-tempo pop musical performance piece with choreographed dance scenes in which Modesta performs with an ensemble of dancers. Some of the scenes and sequences have narrative storylines in which Modesta interacts with a variety of supporting characters, and other scenes have side plots about the followers and fans of Modesta. In short, the combined storylines, backed up by the lyrics of the song, create a narrative plot, which is the establishment of a new world order controlled by Modesta as the human prototype.

In this mixture of uncanny suspense, fragmentation of fleshly and prosthetic body parts, fashionable excess and exclusivity, what comes to mind is not only the intended awareness-raising message: that being born (or becoming) disabled can be negotiated in creative ways of taking risks or that bodily diversity should be considered as a location of originality. What comes to mind is also how the visual imagery of the video is carefully constructed around mainstream visual tropes of pop culture, e.g., through references to Modesta as a superheroine, the stylized and shifting costumes, the dancing ensembles and the fast and fragmented editing and interrupted storylines. What is especially remarkable about this approach is how the particularity of Modesta's body with her prosthetic leg is inscribed directly into this equation. In addition to the black metal spike prosthesis, we see Modesta 'wearing' other noticeable prosthetic legs throughout the rather long video of 6:06 minutes: One is fluorescent and lights up, and one is covered in sparkling crystals. Emphasized by the repeated visual fragmentations of Modesta's body, exhibiting the shift- 
ing prosthetics, the spectator is deliberately invited to stare, ${ }^{3}$ which is an ocular gesture that refers to the ways certain charged positions of visuality and spectatorship are invoked when someone looks at someone with a disability and when someone is looked at as a person with a disability (Garland-Thomson, 2009).

What is especially interesting are the visualized equivalences of popular cultural consumerism and disability, as we get to see Modesta's distinctive prosthetic legs as fashionable and replaceable accessories, just as we see her in varying styles of costumes, makeup and hair. The very condition that places her in a misfit position is, then, transformed into a desirable location of mainstream consumption. While this is indeed an illustrative point about how popular cultural imagery can be "a sight of both resistance and incorporation", to use the words of Katie Ellis (2015, p. 163, original emphasis), it is also relevant to note how the processes of mainstreaming and misfitting in relation to disability and its intersections with gender are balanced in ways slightly different from The Raw Beauty Project.

As noted, Modesta's visual appearance explicitly plays around with the surface aesthetics of visual texts with references and symbols of pop discourse creating direct connotations relating to her gender and sexuality. Surely, Modesta appears as a feminized figure. She is trim, slender, well-groomed and surrounded by fashion and luxury, which undoubtedly can be interpreted as superfluous gendered visual expressions, as in the case of The Raw Beauty Project. Yet, rather than conforming to conventional and distinct codes of gender and femininity, the overt visual aesthetics also contribute to transgressions of unilateral femininity. What is exercised through Modesta's character could be characterized as a form of hyper-feminization, which also takes place as a part of the interplay with disability. At one and the same time, disability and gender seem to be stabilized and destabilized through the stylized staging of bodily particularity. In this regard, mainstreaming and misfitting are displayed as incongruent and shape-shifting relations of being either fit or misfit.

In Modesta's case, the misfit signifies both the intimate bodily-material aspects of disability and the possible transgressions of visual compliance through gender and sexuality. An example is a clip in which Modesta is portrayed sitting close by another female character on a bedside, obviously indicating an intimate sexual relation. They are both naked, and the other woman caresses Modesta, who sits in the front, displaying her leg stump, which is the only scene in the video in which she is not wearing prosthetics. This depiction intensifies the experience of bodily materiality and creates a visual collision between the initial surface aesthetics of the replaceable and eye-catching prosthetic legs as opposed to the corporeal fleshliness of being an amputee. At the same time, the atmosphere created through Modesta's engagement with the female character amplifies the sense of bodily intimacy. Prior to this exact scene, Modesta has been depicted in an intimate bed scene with a male character, who now appears behind the bed, buttoning his shirt, which adds to a destabilization of conventional monogamous heterosexuality. Accordingly, the spectator positions are not allowed to manifest in a traditional sense in which disability and gender are simply reduced to generic categories of either disabled or gendered identity. Instead 
disability and gender become coalescent identity positions that promote productive forms of diversity by persistently challenging and transgressing traditional notions of disabled and gendered embodiment through misfitting.

However, the constant negotiations of identity positions also mean that the prospects for identification shift at a pace in which it is almost only possible to recognize Modesta as a character, or a persona, performing well-organized roles of disability and gender. As opposed to The Raw Beauty Project, which articulated a common and immediate voice for a community of women with disabilities, the representation of Modesta is also a highly individualized portrayal, partly drawing associations to 'supercrip' tales of individuals overcoming disabilities as being exceptionally inspirational people (Ellis, 2012, p. 88; Clare, 2015, pp. 2ff.).

\section{Further reflections and conclusive remarks: Balancing identities of disability and gender through mainstreaming and misfitting}

The analyses of the videos show how processes of mainstreaming and misfitting take place in online disability awareness-raising campaigns by highlighting different aspects of disability and its intersections with gender. While the Raw Beauty Project seeks to stabilize disability as a valid category of identity through the installment of traditional visual codes of femininity, the video with Viktoria Modesta works in ways in which the signifiers of disability and gender are continuously destabilized but, at the same time, strictly controlled by the tight and hyper-aestheticized visuality.

These reflections especially relate to the ways identities of disability and gender are orchestrated and renegotiated differently through processes of mainstreaming and misfitting. In both cases, it becomes clear that these processes are firmly organized by how the markers of disability and gender intersect and are balanced differently as valid identity positions.

In the case of The Raw Beauty Project, it is interesting that traditional femininity becomes an approach to mainstreaming disability. As the analysis has shown, there are serious complications connected to wanting to create a space in which to be misfit as a marginal identity of disability while, at the same time, trying to resolve this by holding onto established gender norms of female beauty. In other words, it is rather striking that the idea that the discrepancies of disability in relation to female beauty could have something to do with the existing discourses of gendered femininity and beauty-ism per se is not considered. This leaves an impression that the Raw Beauty Project relies more on mainstream visual imagery than on the possibility for simultaneous negotiations of disability and gender as productive misfit positions.

In the case of Viktoria Modesta, misfit identity can be seen as a synthesis of visual aesthetic codes and bodily particularities of disability, gender and sexuality. The critical negotiations of identity through misfitting are, thus, framed to challenge the processes of creating 
stable categories. Here, mainstreaming and misfitting become equal strategies for playing around with signifiers of identity in order to create a productive visual representation.

Thus, the overall reflections on the analyses of the videos could easily point to a conclusion in which the Raw Beauty Project is a poor representation compared to the Viktoria Modesta video, which is an exemplary case of progressive visual communication. However, as already implied, one could also ask whether the video with Viktoria Modesta - in the quest for demonstrating particularity and diversity on scales of both disability and gender - ultimately creates new types of exclusionary and individualized narratives that risk masking the shared and social causes of mainstreaming bodily diversity. Holding onto this reflection opens up another layer of conclusions to be addressed.

Whereas Modesta represents an ideal of how to visualize the complexity of misfitting critically, The Raw Beauty Project may, in some regards, come closer to a representation of how identity is negotiated in the everyday life of women living with disabilities. As a case of social community-making, highlighted through the collective statement expressed through the group of women, The Raw Beauty Project takes on a task of creating important common voices for people living with disabilities. This is a field that is otherwise poorly represented in the media (Ellis \& Goggin, 2015, p. 40). While it is doubtful that most people are actually able to identify with the character of Modesta in the music video, it is more likely that the women in The Raw Beauty Project create recognizable and transparent positions from which disability and female beauty can also be viewed as an everyday issue. To be able to recognize oneself in a representation also seems to be a reasonable part of imagining productive positions of misfitting.

In the light of this, what also becomes clear through the analyses is that, while the crossovers and tensions that occur sometimes seem rather mundane, it is also in these gray areas that subtle complexities can be disclosed and conveyed without polarizing visual representations into states of being either good or bad.

In conclusion, I want to return to the importance of bringing this analysis of disability and its intersection with gender in visual media representation to the fore. Although the perspectives offered here are far from exhaustive and much more - including other possible intersecting categories of identity - could be discussed in relation to the videos as media genres, this article makes some points for future investigation. Exploring the two videos through the lens of mainstreaming and misfitting has displayed some important overlaps between disability and gender in visual media representation. I believe that further explorations of mainstreaming and misfitting as a conceptual pair could lead to extended insights into ways that disability intersects with gender - and also other positions of identity in media representations. With the emerging growth of disability in media representations, it seems to become especially important to sharpen our analytical apparatuses and refocus our attention on how different markers of disability play out in intricate and subtle ways. 


\section{Notes}

1 A list of the media coverage of The Raw Beauty Project is provided on the webpage http://www.rawbeautynyc.com/media.html

2 The Born Risky campaign is a part of a self-promotional renewal of Channel 4's self-proclaimed profile as British television's strongest advocate of diversity. In January 2015, the campaign was followed up by a set of "Commissioning Diversity Guidelines" for the entire organization, and a compilation of specific objectives and quota strategies for a new outreach program, headlined "The $360^{\circ}$ Diversity Charter", set goals for employing more people with disabilities both on- and off-screen (www.channel4.com/info/ corporate/about/c4-diversity).

3 Staring refers to Rosemarie Garland-Thomson's conceptualization of the term in her book Staring: How We Look (2009). According to Garland-Thomson, staring is a relational act between a starer and a staree and is in many ways similar to gendered and sexualized acts of gazing, referred to in the introduction. The stare displays how embedded mechanisms of visuality are always predisposed, and it exhibits an arena in which perceptions of bodily norms and differences are shaped and preserved (Garland-Thomson, 2009, pp. 9ff). Yet, whereas acts of gazing are almost always an ocular gesture of dominance and asymmetrical power relations, Garland-Thomson stresses that staring has much more subtle capacities "from domination, adoration, curiosity, surprise, allegiance, disgust, wonder, befuddlement, openness, hostility, to reverence" (Garland-Thomson, 2009, p. 39).

\section{References}

Adams, R. (2013). Disability studies now. American Literary History, 25(2), 495-507.

Beer, D. (2013). Popular Culture and New Media. The Politics of Circulation. Palgrave Macmillan.

Ben-Moshe, L., \& Magaña, S. (2014). An introduction to race, gender, and disability: Intersectionality, disability studies, and families of color. Women, Gender, and Families of Color, 2(2), 105-114.

Berger, J. (1972). Ways of Seeing. Penguin Books Ltd.

Campell, F.K. (2009). Contours of Ableism. The Production of Disability and Abledness. Palgrave Macmillan.

Clare, E. (2015). Exile \& Pride. Disability, Queerness and Liberation. Durham and London: Duke University Press.

Crenshaw, K. (1991). Mapping the margins: Intersectionality, identity politics, and violence against women of color. Stanford Law Review, 43(6), 1241-1299.

Ellis, K. (2012). Dolls with disabilities: Playing with diversity. In N. Norris (Ed.), Unionist Popular Culture and Rolls of Honour in the North of Ireland during the First World War: A Collection of Diverse Essays in Popular Culture (pp. 81-97). UK: Edwin Mellen Press.

Ellis, K. (2014). The voice Australia (2012): Disability, media and collective intelligence. Continuum: Journal of Media \& Cultural Studies, 28(4), 482-494.

Ellis, K. (2015), Disability and Popular Culture. Focusing Passion, Creating Community and Expressing Defiance. Ashgate.

Ellis, K., \& Goggin, G. (2015). Disability \& the Media. Palgrave Macmillan.

Garland-Thomson, R. (1997). Extraordinary Bodies. Figuring Physical Disability in American Culture and Literature. Columbia University Press.

Garland-Thomson, R. (2002). Integrating disability, transforming feminist theory. NWSA Journal: Feminist Disability Studies, 14(3), 1-32.

Garland-Thomson, R. (2009). Staring: How We Look. Oxford University Press.

Garland-Thomson, R. (2011). Misfits: A feminist materialist disability concept. Hypatia, 26(3), 593-609. 
Goggin, G., \& Newell, C. (2003). Digital Disability: The Social Construction of Disability in New Media. Rowman \& Littlefield.

Goodley, D. (2011). Disability Studies. An Interdisciplinary Introduction. London: Sage.

Goodley, D. (2013). Dis/entangling critical disability studies. Disability \& Society, 28(5), 631-644.

Goodley, D., Hughes, B., \& Davis, L. (Eds.) (2012). Disability and Social Theory. Hampshire. New York: Palgrave Macmillan.

Haller, B.A., \& Ralph, S. (2006). Are disability images in advertising becoming bold and daring? An analysis of prominent themes in US and UK campaigns. Disability Studies Quarterly, 26(3), Society for Disability Studies.

Hladki, J. (2009). Mattering media: Thinking disability in political visual practice. Review of Education, Pedagogy, and Cultural Studies, 31(2-3), 107-126.

Kafer, A. (2003). Compulsory bodies: Reflections on heterosexuality and able-bodiedness. Journal of Women's History, 15(3), 77-89.

Kafer, A. (2013). Feminist Queer Crip. Indiana University Press.

Meekosha, H., \& Shuttleworth, R. (2009). What's so 'critical' about critical disability studies? Australian Journal of Human Rights, 15(1), 47-75.

Meyer, S. (2010). Visuell Makt. Bilder, blikk og betraktere. Oslo: Universitets-forlaget.

McRuer, R. (2006). Crip Theory. New York, London: New York University Press.

Mohamed, K., \& Schefer, T. (2015). Gendering disability and disabling gender: Critical reflections on intersections of gender and disability. Agenda: Empowering Women for Gender Equity, 29(2), 2-13.

Moodley, J., \& Graham, L. (2015). The importance of intersectionality in disability and gender studies. Agenda: Empowering Women for Gender Equity, 29(2), 24-33.

Mulvey, L. (1989). Visual pleasure and narrative cinema. In Visual and Other Pleasures (pp. 14-30). The MacMillan Press Ltd.

Poell, T., \& van Dick, J. (2015). Social media and activist networks. In C. Atton (Ed.), The Routledge Companion to Alternative and Community Media (pp. 527-37). London: Routledge.

Rice, R., \& Atkin, C. (2013). Public Communication Campaigns ( $4^{\text {th }}$ Edition). Sage Publications Ltd.

Rich, A.C. (2003). Compulsory heterosexuality and lesbian existence (1980). Journal of Women's History, 15(3), 11-48.

Rose, G. (2016). Visual Methodologies ( $4^{\text {th }}$ edition). Sage Publications Ltd.

Sayers, R. (2006). Principles of Awareness-Raising: Information Literacy, A Case Study. Bangkok: UNESCO, Communication and Information.

Siebers, T. (2008). Disability Theory. The University of Michigan Press.

Urrichio, W. (2009). The future of a medium once known as television. In P. Snickars, \& P. Vonderau (Eds.), The YouTube Reader (pp. 24-39). National Library of Sweden, Mediehistoriskt arkiv 12.

Zhang, L., \& Haller, B. (2013). Consuming image: How mass media impact the identity of people with disabilities. Communication Quarterly, 61(3), 319-334.

\section{Web}

The Raw Beauty Project NYC (2014). Retrieved from http://www.rawbeautynyc.com/

The Raw Beauty Project NYC (2014). YouTube. Retrieved from

https://www.youtube.com/watch?v=7_3REkm-msY

Born Risky, Channel 4 (2014). Retrieved from http://www.channel4.com/programmes/bornrisky

Prototype (2014). YouTube. Retrieved from https://www.youtube.com/watch?v=jA8inmHhx8c 
Article: Mainstreaming and misfitting

Maria Bee Christensen-Strynø

PhD Fellow

Department of Communication and Arts

Roskilde University, Denmark

mariabee@ruc.dk 